\title{
Efeito barreira e o atravessamento de pedestres no Anel Rodoviário Celso Mello Azevedo, Belo Horizonte (Brasil)
}

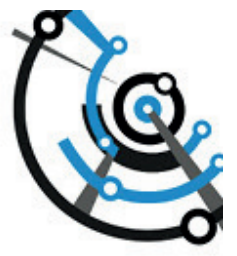

\section{(4) Bárbara Abreu Matos}

Departamento de Engenharia Urbana, Universidade Federal de Ouro Preto, Brasil. ORCID: https://orcid.org/00oo-0002-0814-8195

\section{Carlos Lobo}

Departamento de Geografia, Universidade Federal de Minas Gerais, Brasil. ORCID: https://orcid.org/oooo-0002-5368-8879

Recibido: 13 de junio de 2020. Aceptado: 18 de mayo de 2021.

\section{Resumo}

Rodovias inseridas no espaço urbano têm comumente se tornado obstáculos ao acesso e a mobilidade, especialmente para os deslocamentos por modos não motorizados. Esse fenômeno, conhecido como "efeito barreira", se intensifica com o crescimento demográfico, expansão do tecido urbano e acréscimo da frota de veículos automotores, como ocorreu em diversas cidades brasileiras ao longo das últimas décadas. Nesse contexto, são objetivos do presente trabalho estimar o volume dos atravessamentos de pedestres entre as margens do Anel Rodoviário Celso Mello Azevedo, importante via utilizada nos deslocamentos urbanos em Belo Horizonte (Brasil), bem como propor a aplicação de indicadores para avaliar o risco potencial para a travessia de pedestres. Para tanto, foram utilizadas as bases de dados de viagens da Pesquisa OD 2012 (RMBH) e a malha digital vetorial de volume de tráfego da rodovia, e os resultados foram comparados com a ocorrência de acidentes por trecho da rodovia. Os resultados apontaram que os trechos 3 e 1 possuem a maior movimentação de pedestres entre as margens, no entanto, a aplicação dos indicadores apontou maior risco de travessia nos trechos 2 (risco alto) e 5 (risco médio) devido ao elevado volume de tráfego e baixa disponibilidade de passarelas, respectivamente. 


\title{
Barrier effect and pedestrian crossing on the Celso Mello Azevedo Ring Road, Belo Horizonte (Brazil)
}

\begin{abstract}
Highways inserted in the urban space have commonly become obstacles to access and mobility, especially for travel by non-motorized modes. This phenomenon, known as the "barrier effect", intensifies with demographic growth, expansion of the urban fabric, and increase in the fleet of motor vehicles, as has occurred in several Brazilian cities over the past decades. In this context, the objectives of the present work are to estimate the volume of pedestrian crossings between the margins of the Celso Mello Azevedo Ring Road, an important route used in urban displacements in Belo Horizonte (Brazil), as well as to propose the application of indicators to assess the potential risk for pedestrian crossing. For this purpose, the travel databases of the OD 2012 Survey (RMBH) and the digital vector mesh of the traffic volume of the highway were used, and the results were compared with the occurrence of traffic-accidents per stretch of the highway. The results showed sections 3 and 1 have the highest pedestrian traffic between the margins, however, the application of the indicators pointed to a higher risk of crossing in sections 2 (high risk) and 5 (medium risk) due to the high volume of traffic and low availability of walkways, respectively.
\end{abstract}

Keywords: Urban roads. Barrier effect. Community severance. Pedestrian crossing. Active mobility. Palabras clave: Carreteras urbanas. Efecto barrera. Segregación socioespacial. Cruce peatonal. Movilidad activa.

\section{Introdução}

O modo rodoviário tornou-se a principal forma de transporte de pessoas e cargas no Brasil, tendo se intensificado pelo contínuo e expressivo crescimento na frota de veículos automotores. No decênio 2009-2018, por exemplo, houve um acréscimo de $63,6 \%$ no número de veículos registrados no país, passando de 59,3 milhões para mais de 98 milhões (CNT, 2018). Esse cenário, reflexo da histórica adoção de políticas que buscaram privilegiar o transporte motorizado (e individual) em detrimento aos demais modos, compreende uma série de obstáculos à acessibilidade e mobilidade espacial da população, especialmente nas metrópoles e nas grandes cidades, marcadas por enormes transtornos de trânsito e tráfego.

Atualmente, é possível notar uma série de conflitos decorrentes do crescimento no fluxo de veículos com a mobilidade e acessibilidade da população no espaço urbano, evidentes quando observadas as disputas entre veículos motorizados, pedestres e ciclistas (Silva Júnior e Ferreira, 2008). A presença de automóveis no ambiente construído gera impactos negativos em relação ao uso da via por aqueles que se deslocam de forma ativa, e, consequentemente, reflete em uma redução na interação social e no uso dos espaços públicos. Ganha evidência, então, o fenômeno denominado efeito barreira (ou de intrusão), "uma vez que o tráfego inibe ou impede a interação social e o uso dos modos não motorizados” (Vasconcellos, 2006:31).

O efeito barreira é notório em rodovias inseridas no espaço urbano, uma vez que as vias são caracterizadas pela regulamentação de velocidades elevadas para os veículos e ausência de travessias em nível para pedestres. A necessidade de deslocamento de pessoas de uma margem à outra, dada a expansão do tecido urbano, é supostamente suprida com a construção de travessias subterrâneas ou passarelas, sendo o último dispositivo amplamente utilizado nas principais rodovias brasileiras. Entretanto, passarelas 
mal concebidas e mantidas com precariedade fazem com que usuários potenciais acabem por evitar sua utilização e se arrisquem entre os veículos para atingir o destino desejado. Diante do exposto, é objetivo deste trabalho estimar os atravessamentos de pedestres entre as margens do Anel Rodoviário Celso Mello Azevedo, localizado na área urbana do município de Belo Horizonte (Brasil), bem como propor indicadores para avaliar o risco de atravessamento de pedestres, considerando o próprio volume de atravessamento, a existência de dispositivos de segurança (passarelas) e o fluxo de veículos em trechos predefinidos da rodovia.

O Anel Rodoviário Celso Mello Azevedo é uma rodovia de jurisdição federal inserida no espaço urbano do município de Belo Horizonte, capital do estado de Minas Gerais (Brasil). Inicialmente construído para reduzir o fluxo de veículos de passagem pela Área Central da cidade, oriundos das rodovias federais BR-040, BR-262 e BR-381, o Anel Rodoviário teve seu uso modificado ao longo dos anos desde sua inauguração, se tornando um dos corredores de trânsito urbano mais movimentados da cidade e da região metropolitana. Essa inversão de uso (de rodovia para via urbana) se deu, principalmente, pelo expressivo crescimento populacional ocorrido nos municípios da Região Metropolitana de Belo Horizonte bem como nas mais diversas regiões da capital mineira, potencializado pela sua localização estratégica que contempla seis das nove regionais administrativas do município e cruza com algumas das principais vias da cidade ao longo dos seus 26,1 km duplicados de extensão (DNIT, 2018), a saber: Av. Amazonas; Av. Presidente Carlos Luz; Av. Presidente Antônio Carlos; Av. Cristiano Machado; dentre outras.

O Anel Rodoviário de Belo Horizonte, bem como em outros grandes núcleos urbanos, assumiu, como consequência do crescimento da frota e expansão da fronteira urbana, a função de uma importante via de deslocamento urbano da população, o que contradiz a função original desse espaço: criado para ser uma rodovia de ligação regional. Soma-se a essa contradição de função as consequências inerentes desse tipo de barreira. Trata-se de uma via responsável por parcela significativa dos acidentes de trânsito no município, principalmente em relação aos atropelamentos com vítimas fatais. Vários eventos criaram a fama (não sem justa causa), exposta na mídia e presente no domínio do senso comum, de uma zona trágica de circulação na capital.

\section{Rodovias em áreas urbanas e efeito barreira: conceito e formas de contradição no espaço}

O processo de organização espacial é ativo e constante, e se configura pelo conjunto de obras humanas dispostas no território, formando, então, uma estrutura urbana (Martine e McGranaham, 2010). Para Sousa e Braga (2011), além da estrutura, o espaço urbano possui forma, função e processo: a forma é definida como o aspecto visível que pode se estabelecer em um padrão espacial; a função é determinada pelas atividades a serem desempenhadas; e o processo, caracterizado como a ação contínua na qual implica no movimento e nas ações das pessoas. Carlos (2015) afirma, ainda, que o espaço urbano não se organiza de forma harmoniosa devido à existência de conflitos inerentes aos diferentes interesses e necessidades dos agentes sociais envolvidos. Os sistemas de transportes, por desempenharem um papel fundamental na organização espacial da estrutura urbana (Villaça, 1998), refletem estes conflitos de maneiras distintas e perceptíveis, inclusive, quando analisadas a disputa entre veículos e pedestres, como pela histórica transformação de ruas em vias de tráfego.

Para Costa et al. (2007), as cidades são espaços com um elevado nível de acumulação e concentração de atividades econômicas e são estruturas espaciais apoiadas por sistemas 
de transportes, também complexos, que envolvem diferentes modos, bem como uma multiplicidade de origens e destinos e à quantidade e variedade de tráfego. Essa complexidade, associada à predileção pelos modos motorizados de transporte, tem agravado os conflitos no espaço urbano, tornando-os mais evidentes nas vias de circulação, nas quais os veículos motorizados (em seus mais diversos tipos) e os pedestres disputam o mesmo espaço (Silva Júnior e Ferreira, 2008). Vasconcellos (2006) também evidencia a existência de uma influência mútua (e complexa) entre o ambiente construído e os diferentes modos de transportes. O autor considera que "se por um lado esta influência mútua é leve quando os modos de transporte não motorizados prevalecem, ela é muito mais forte quando os modos motorizados tornam-se dominantes" (Vasconcellos, 2006:31). O efeito barreira, por sua vez, surge no momento em que os sistemas de transportes, incluindo a infraestrutura necessária para o seu funcionamento, interferem nas condições de mobilidade e acessibilidade da população, que tende a reduzir-se na medida que cresce o volume de veículos.

Cabe ressaltar que os conceitos de mobilidade e acessibilidade são comumente cercados de dúvidas e equívocos entre diversos autores e áreas do conhecimento, conforme aponta Cardoso (2007). Enquanto a mobilidade pode ser definida pelo "conjunto de deslocamentos de pessoas e bens, com base nos desejos e nas necessidades de acesso ao espaço urbano, mediante a utilização dos vários meios de transporte" (Belo Horizonte, 2011: Art. $1^{\circ}$ ), acessibilidade está relacionada com a "oportunidade um indivíduo tem de participar de uma atividade particular, alcançando um determinado destino ou atividade" (Sousa e Braga, 2011:62). Ainda, a acessibilidade (ou sua falta) é potencializada pela disponibilidade do sistema de transportes e pelo uso e ocupação do solo (Cardoso, 2007). A organização espacial da cidade, bem como a disposição espacial das obras humanas, influencia diretamente nos níveis de acessibilidade. Pooler (1995) acredita que a acessibilidade funciona como agente e medida de segregação socioespacial, consequentemente, associando a acessibilidade à qualidade de vida da população.

Entretanto, algumas infraestruturas de transporte podem gerar consequências negativas para a acessibilidade da população. Esse fenômeno é conhecido com efeito barreira, sendo caracterizado pela inibição ou impedimento das interações sociais e do uso dos modos não motorizados pela presença do tráfego de veículos (Vasconcellos, 2006). Comumente associado ao sistema de transportes, o termo "efeito barreira" é análogo ao "community severance", que se traduz como separação ou rompimento socioespacial, isto é, uma descontinuidade na estrutura urbana provocada pelas redes de transportes (Anciaes et al., 2018). Mindell e Karlsen (2012) destacam que a separação das comunidades pode ser ocasionada pela velocidade e/ou pelo volume do tráfego de veículos, que, consequentemente, reduzem a atividade física, contatos sociais, brincadeiras infantis e acesso a bens e serviços. Anciaes et al. (2016), ao afirmarem que o tráfego rodoviário motorizado contribui para a separação física e psicológica dos bairros, acreditam que também geram possíveis efeitos sobre a saúde e o bem-estar dos moradores locais.

Dessa forma, entende-se que o efeito barreira pode ocorrer de três maneiras: pela própria instalação da infraestrutura de transporte, conhecido como barreira física; pelo fluxo de tráfego que utiliza a via, ocasionando uma barreira de fluxo de tráfego; pelos aborrecimentos e desconfortos por elas causados à população, gerando, dessa forma, uma barreira psicológica (Grisolía et al., 2014). Mouette e Waisman (2004) afirmam que o efeito restringe a locomoção dos indivíduos, causando uma consequente diminuição na quantidade de deslocamentos e na acessibilidade a pontos e estabelecimentos presentes "do outro lado" do local a ser transposto. Nota-se que o fenômeno ocorre em diferentes infraestruturas de transportes, com ruas, avenidas, viadutos, trincheiras, linhas férreas e, inclusive, em corredores de transporte coletivo como do sistema BRT (Sousa e Braga, 2011 e Anciaes, 2015). Contudo, a presença de rodovias em áreas urbanas torna o efeito barreira ainda mais evidente não apenas pelo local 
ser uma barreira decorrente do tráfego de veículos e da própria infraestrutura da via, mas também pelo risco ao qual o pedestre é exposto ao caminhar, sobretudo durante a travessia entre as margens.

De acordo com Vasconcellos (2006), a composição e o volume de tráfego são elementos relevantes que interferem na segurança das travessias de pedestres. A transposição entre as margens da rodovia é realizada com o auxílio de dispositivos específicos, também conhecidos por passagens subterrâneas e passarelas, sendo a última usualmente utilizada no território brasileiro. Para o Departamento Nacional de Infraestrutura de Transportes - DNIT (2010), os projetos rodoviários consideram os pedestres os elementos mais frágeis que se deslocam na via pública, inclusive por apresentarem padrões de deslocamento caracterizados pela irregularidade de trajeto. Apesar disso, por historicamente priorizar o transporte rodoviário e motorizado, o planejamento tradicional contribui para a redução dos deslocamentos a pé e para o isolamento e desintegração das comunidades, tema em voga nas pesquisas acadêmicas.

Mouette e Waisman (2004) apontam que o efeito barreira realmente desencadeia uma série de consequências negativas para a população que reside no entorno das vias caracterizadas como barreiras, ocasionando impedâncias ao livre movimento dos pedestres, principalmente, das crianças e dos idosos. Maciorowski (2018) constata que a sensação de insegurança dos pedestres nas rodovias urbanas é ocasionada, principalmente, pela falta de opções de travessia. Por sua vez, Mindell e Anciaes (2020) pontuam que a massiva utilização de veículos motorizados resulta em um ambiente desagradável para o caminhar devido ao ruído e a poluição do ar, e a falta de segurança e o ambiente viário hostil refletem na inequidade de uso da rua como espaço social.

Os dispositivos que auxiliam os pedestres em uma travessia com segurança, não raro, acabam por penalizar a parte mais frágil desse complexo sistema. As passarelas e passagens subterrâneas comumente exigem que o pedestre aumente consideravelmente a distância de caminhamento para alcançar a travessia desejada, além de, em frequentes ocasiões, não apresentar condições adequadas de segurança. Outro importante ponto a se destacar é o posicionamento desses dispositivos na via (Mindell e Anciaes, 2020). Devido a diversidade de desejos de deslocamentos das pessoas, as passarelas podem não atender com eficiência essa necessidade ao longo de toda via. Na maioria dos casos, as pessoas que moram perto de rodovias urbanas movimentadas preferem utilizar travessias em nível a esses dispositivos (Vaughan et al., 2020). Com isso, estruturas mal concebidas, mal posicionadas e mantidas com precariedade, fazem com que usuários potenciais acabem por evitar sua utilização e se arrisquem entre os veículos para atingir o destino desejado.

Grisolía et al. (2014) pontuam que o volume e a velocidade do tráfego aumentam a duração das viagens a pé ao longo das rodovias urbanas à medida que as pessoas precisam desviar dos caminhos mais curtos para atravessar a via em locais seguros. Para isso, constroem-se passarelas e passagens subterrâneas. Contudo, essas infraestruturas geram, além do aumento na distância e no tempo de travessia, degradação do ambiente dos pedestres, redução da mobilidade e impactos visuais negativos para os usuários não motoristas. Raramente essas instalações removem a separação entre as margens por completo e não são percebidas pela população como uma melhoria do ambiente urbano para os pedestres (Grisolía et al., 2014).

Nesse sentido, o efeito barreira está, em outros casos, associado a um fenômeno negativo de percepção do meio ambiente pelos indivíduos, que, em geral, não compreendem a falta de equidade na divisão do espaço de circulação entre veículos e pessoas. Para Vasconcellos (2006): 
(...) Este fenômeno se traduz pela percepção de que tudo está "normal", sem a identificação clara de como o ambiente de circulação foi criado e quem está sendo prejudicado ou beneficiado. A circulação por um determinado ambiente não permite identificar como ele foi construído e é comum ver as pessoas dizerem, ao andarem sobre uma via sem pedestres, que as condições são "normais". Esta percepção ignora que os pedestres não estão lá porque foram expulsos pelo tráfego perigoso, para se defenderem. Este é um dos impactos mais perversos do efeito barreira, pois dificulta a conscientização das pessoas sobre o grau de equidade na divisão do espaço de circulação entre os vários papéis. (Vasconcellos, 2006:34).

Em suma, observa-se que a construção de rodovias em áreas urbanas rompe com o tecido social, podendo trazer consequências negativas para as comunidades envolvidas. Desse modo, um novo ambiente é criado, baseado na lógica de circulação dos veículos. As pessoas passam a desenvolver estratégias para minimizar as impedâncias de circulação, que envolvem a redução das distâncias e tempos de travessia, inclusive se arriscando entre os veículos para transpor as margens da via, incorrendo em maiores riscos e acidentes de trânsito. Em locais em que há grande movimentação de pedestres e de veículos, como o local de estudo do presente trabalho, a situação pode se tornar crítica.

\section{Área de estudo, unidades espaciais de análise, base de dados e procedimentos metodológicos}

Desde sua criação, na década de 1950, com o propósito de reduzir o volume de veículos na Área Central com destino às demais rodovias que cruzam a cidade, o Anel Rodoviário Celso Mello Azevedo, que compõe o objeto de estudo dessa pesquisa, tem passado por diversas transformações em boa medida devido ao acréscimo do volume de veículos e de construções residenciais, tanto nos bairros lindeiros, quanto na própria margem da rodovia, que na maioria dos casos são irregulares. Atualmente, o Anel Rodoviário, como é popularmente denominado, se estende do entroncamento com a BR-040 (sentido Rio de Janeiro-RJ), na região do bairro Olhos D'água, na porção sul do município, até a bifurcação com as rodovias BR-262 (sentido VitóriaES) e BR-381 (sentido São Mateus-ES), no bairro Nazaré, localizado na regional nordeste. A rodovia é, ainda, interceptada por importantes avenidas urbanas do município, com destaque para a Av. Amazonas, Av. Presidente Antônio Carlos e Av. Cristiano Machado e é considerada uma importante ligação entre Belo Horizonte e os municípios da Região Metropolitana de Belo Horizonte (RMBH), como Nova Lima, Contagem e Sabará (Figura 1).

A via é composta por duas pistas de tráfego com duas a três faixas por sentido de fluxo, a variar por trecho, visto que em alguns locais há estreitamento das faixas de rolamento. A velocidade operacional máxima no Anel Rodoviário é regulamentada em $80 \mathrm{~km} / \mathrm{h}$, sendo que em alguns trechos, considerados de maior risco, a velocidade máxima permitida se limita à $70 \mathrm{~km} / \mathrm{h}$ para veículos de passeio e $60 \mathrm{~km} / \mathrm{h}$ para veículos de carga.

O volume de tráfego motorizado na via é intenso, circulando em média 105 mil veículos/dia no trecho de maior fluxo (DNIT, 2018). Moreira e Brasil (2019), ressaltam a importância do Anel Rodoviário como principal corredor de cargas da região, principalmente para o abastecimento interno, visto que aproximadamente 40 mil viagens/ dia são realizadas na via para o transporte de produtos e mercadorias da RMBH. Andrade et al. (2019), pontuam que, ao longo dos últimos anos, o tráfego urbano no Anel Rodoviário se intensificou, contudo, a escassez de investimentos para manutenção local fez com que a infraestrutura da rodovia ficasse defasada, situação evidenciada pela descontinuidade de pistas marginais e estreitamentos das pistas centrais nas 
interseções com os corredores urbanos. Somado a predileção pelo uso do transporte motorizado individual, responsável por $36,5 \%$ dos deslocamentos diários da população belo-horizontina (Agência RMBH, 2012), a rodovia tornou-se uma grande avenida urbana, principalmente nos horários de pico, onde são registrados altos índices de congestionamento e de acidentalidade (Miranda et al., 2017).

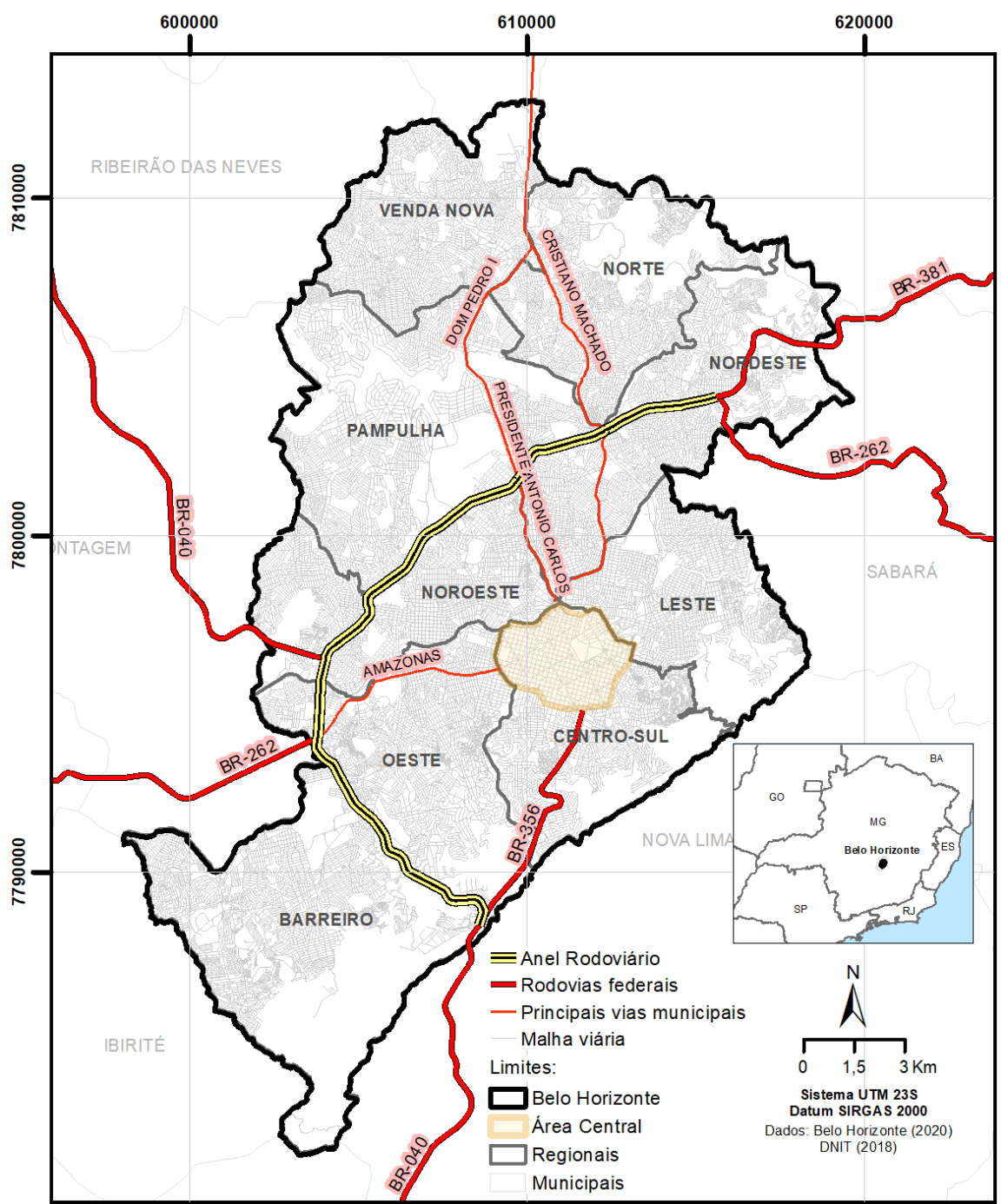

Figura 1. Mapa de localização do Anel Rodoviário Celso Mello Azevedo e da sua respectiva zona de influência no município de Belo Horizonte (MG). Fonte: Elaboração própria.

Soma-se a essa contradição da função da via, o volume significativo de acidentes de trânsito que ocorrem no local. De acordo com o banco de dados de acidentes de trânsito com vítimas ocorridos nas vias de Belo Horizonte, em 2018 foram registrados 11.656 acidentes de trânsito no município, sendo o Anel Rodoviário a via onde se localizaram 7\% desse total (769) (BHTRANS, 2018). Desse número, ocorreram um total de 63 atropelamentos na rodovia, sendo $52 \mathrm{sem}$ vítimas fatais e $11 \mathrm{com}$ vítimas fatais. Os dispositivos utilizados para transpor as margens do Anel Rodoviário de Belo Horizonte pelos pedestres são as passarelas instaladas ao longo de sua extensão. Entretanto, o alto índice de atropelamentos com vítimas fatais, que corresponde a $25 \%$ de todos os eventos dessa espécie ocorridos no município de Belo Horizonte para o ano de 2018, pode ser considerado um indicativo alarmante no que tange às condições de 
caminhabilidade local. Esse cenário faz refletir sobre o atendimento aos pedestres em relação aos desejos (e necessidades) de atravessamento entre as margens da rodovia e traz luz à problemática da inserção de uma via com velocidade operacional tão elevada dentro de um ambiente urbano.

Para identificar os atravessamentos de pedestres na via, foi utilizada a base de dados da última pesquisa de Origem e Destino (OD), referente ao ano de 2012, realizada pela Agência de Desenvolvimento da Região Metropolitana de Belo Horizonte, órgão vinculado ao Governo do Estado de Minas Gerais. Trata-se de uma pesquisa decenal que contém dados básicos para o planejamento e gestão do transporte e do tráfego municipal e metropolitano, com o propósito de subsidiar políticas públicas de planejamento metropolitano (Agência RMBH, 2012). Ressalta que a pesquisa OD é a única base de dados disponível para mensurar esses atravessamentos e mesmo que a versão mais recente tenha sido realizada no ano de 2012, os dados ainda conseguem se aproximar à realidade local. A unidade de análise utilizada para estimar os fluxos de origem e destino de travessia de pedestres foram as Áreas Homogêneas (AH’s) (Figura 2), que são agregações de setores censitários e menor nível de desagregação espacial utilizado na pesquisa OD.

O DNIT (2010), órgão federal vinculado ao Ministério da Infraestrutura que estabelece diretrizes básicas para a elaboração de estudos e projetos rodoviários em todo território nacional, considera no planejamento de projetos de rodovias em áreas urbanas que os pedestres se deslocam no máximo por 1.000 metros para alcançar pontos de ônibus. Por sua vez, a BHTRANS (2008), órgão da administração municipal responsável pelo planejamento da mobilidade urbana e pela gestão do transporte e trânsito, regulamenta que esse deslocamento seja limitado a 600 metros para acesso aos pontos de transporte coletivo municipais. Sendo assim, optou-se por considerar a distância de 600 metros para seleção da zona de influência do Anel Rodoviário por se tratar de um valor que melhor aproxima de um limite de distância para embarque no sistema de transporte público e para deslocamentos cotidianos a pé.

A zona de influência dessa área potencial de atravessamento, também representada na Figura 2, foi delineada a partir do eixo principal do Anel Rodoviário utilizando aplicativo QGis (ferramenta "buffer"), e serviu de referência, pela relação topológica de bordeamento, para selecionar as respectivas áreas homogêneas que a intersectam, por meio da ferramenta "select by location". As AH's foram segregadas entre as margens "direita" e "esquerda" (sentido sul-norte), representadas em tons de cinza na Figura 2, de maneira a possibilitar a identificação dos fluxos de travessia de pedestres no Anel.

No total, foram selecionadas 119 AH's, que correspondem a 21\% das áreas homogêneas do município, o que demonstra o potencial de influência da rodovia na mobilidade e acessibilidade espacial em Belo Horizonte. Desse total, 57 AH’s estão localizadas na margem direita da via e 62 AH's na margem esquerda. O aplicativo QGis também foi utilizado para incorporar atributos a cada vetor que representa as viagens para cada $\mathrm{AH}$ (ferramenta "join"), obtidas pela base de dados da pesquisa OD 2012, em que foram consideradas apenas as viagens realizadas pelo modo a pé em que a origem ocorreu na margem esquerda com destino à margem direita (possíveis fluxos de atravessamento), bem como no sentido oposto. 


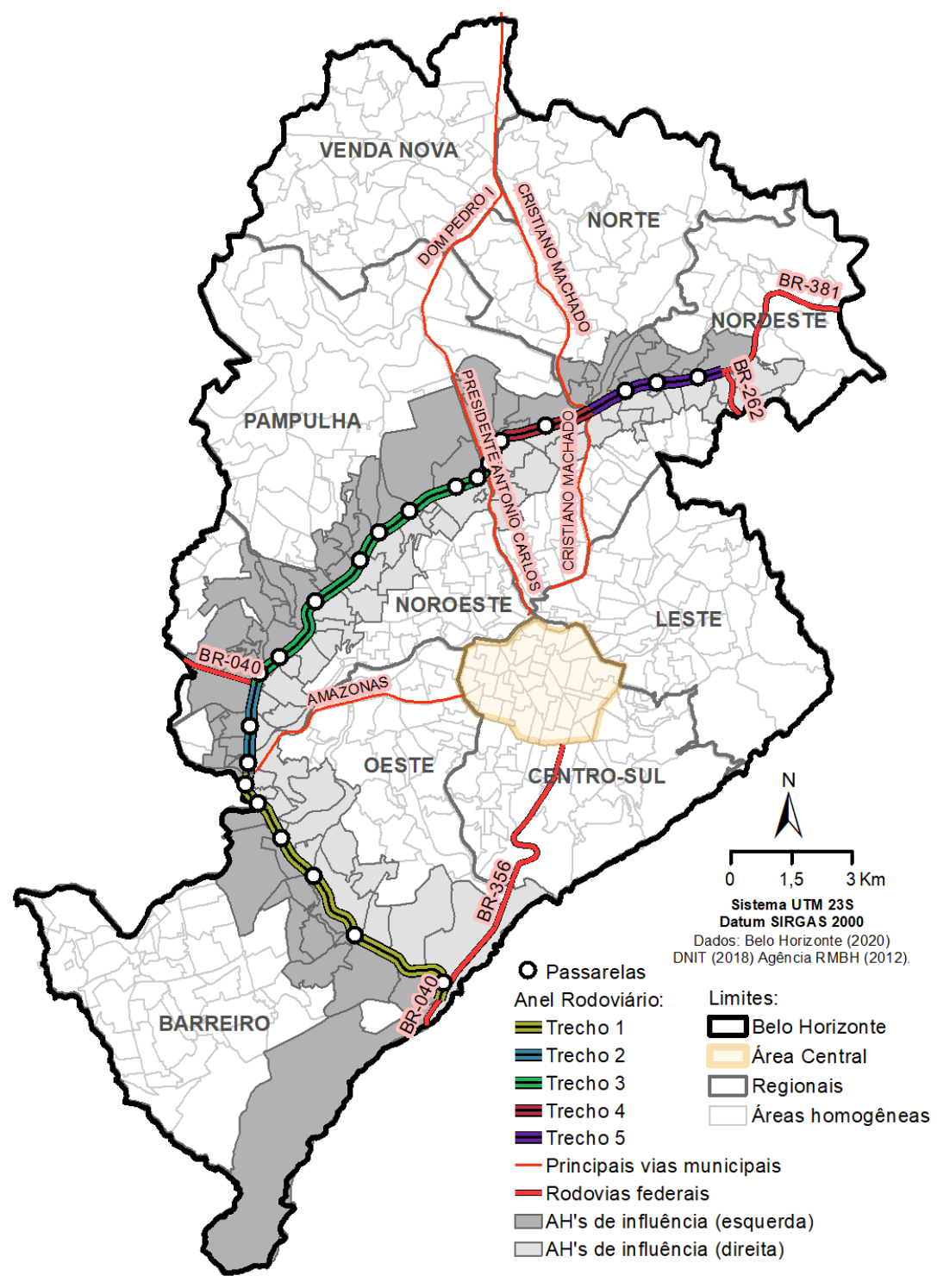

Figura 2. Trechos de análise do Anel Rodoviário, com destaque para as AH's da zona de influência de 600 metros do eixo da rodovia. Fonte: Elaboração própria.

Para fins de análise, optou-se, ainda, por desmembrar o Anel Rodoviário em cinco trechos, considerando os cruzamentos com as principais rodovias e vias da cidade, sendo: Trecho 1, entre BR-356 e Av. Amazonas; Trecho 2, entre Av. Amazonas e BR-040; Trecho 3, entre BR-040 e Av. Presidente Antônio Carlos; Trecho 4, entre Av. Presidente Antônio Carlos e Av. Cristiano Machado; Trecho 5, entre Av. Cristiano Machado e BR-262/BR-381 (Figura 2). O seccionamento da rodovia seguiu o padrão estabelecido pelo DNIT (2018), o que possibilitou obter as informações da estimativa de Volume Médio Diário anual (VMDa) de veículos por trecho para o ano de 2018, dado disponibilizado no Plano Nacional de Contagem de Tráfego (PNCT). Por sua vez, o levantamento da localização das passarelas que atendem o Anel Rodoviário foi obtido por meio de fotointerpretação direta, com base em imagens do Google Satellite, disponíveis de forma gratuita e acessadas por conexão com WMS/WMTS via QGis. No total foram identificadas 22 passarelas, dispostas em distâncias irregulares umas das outras (Figura 2). 
Para mensurar os impactos do efeito barreira que o Anel Rodoviário de Belo Horizonte causa nos pedestres, foi realizada a análise do risco de atravessamento a partir da proposição dos indicadores Risco da Via (RV), Risco da Travessia (RT) e Índice de Risco da Travessia (IRT). O risco de travessia de pedestre pode ser potencializado pela relação entre a quantidade de veículos que circulam na via, dada sua extensão, bem como pela velocidade do tráfego. Por sua vez, esse risco pode ser atenuado, dentre outros aspectos, por dispositivos de auxílio ao atravessamento, como as passarelas. Assim, considerando a velocidade constante regulamentada para o Anel Rodoviário, limitada de $60 \mathrm{~km} / \mathrm{h}$ a $80 \mathrm{~km} / \mathrm{h}$ em função do trecho é do tipo de veículo, propõem-se a Equação 1 para estimar, primeiramente, o Risco da Via (RV):

$$
R V_{n}=\frac{\frac{V M D a_{n}}{E_{n}}}{p_{n}^{2}}
$$

em que:

$$
\begin{aligned}
& R V_{n}: \text { Risco da Via em um trecho } n ; \\
& V M D a_{n}: \text { Volume Médio Diário anual de tráfego de veículos em um trecho n; } \\
& E_{n}: \text { Extensão, em quilômetros, de um trecho } n ; \\
& p_{n}: \text { Número de passarelas que atendem um trecho } n .
\end{aligned}
$$

Dependendo da localização da passarela na via, a mesma pode atender mais de um trecho. Nesse sentido, para cálculo do Risco da Via foram consideradas como passarelas que atendem um trecho $n$ tanto as localizadas no próprio trecho quanto as localizadas nos trechos imediatamente anterior e/ou posterior, desde que a distância entre o limite do trecho e a passarela fosse de, no máximo, 600 metros.

O risco do pedestre ao atravessar a rodovia se relaciona, ainda, com a demanda por acesso à margem oposta, ou seja, pela quantidade de atravessamentos pelo modo a pé. Sendo assim, o Risco da Travessia (RT) foi estimado conforme a Equação 2 proposta a seguir:

$$
R T_{n}=R V_{n} \times \frac{V p_{n}}{E_{n}}
$$

em que:

$$
\begin{aligned}
& R T_{n}: \text { Risco da Travessia em um trecho n; } \\
& R V_{n}: \text { Risco da Via em um trecho n; } \\
& V p_{n}: \text { Viagens de atravessamento pelo modo a pé com origem em um trecho n; } \\
& E_{n}: \text { Extensão, em quilômetros, de um trecho n. }
\end{aligned}
$$


Para fins de padronização dos escores obtidos, utilizou-se a Equação 3 para conversão dos valores de cada Risco de Travessia em uma escala de 0 a 1 (menor e maior risco, respectivamente), surgindo, então, o Índice de Risco da Travessia (IRT):

$$
I R T_{n}=\frac{R T_{n}-R T_{\min }}{R T_{\max }-R T_{\min }}
$$

em que:

$$
\begin{aligned}
& I R T_{n}: \text { Índice de Risco da Travessia em um trecho n; } \\
& R T_{n}: \text { Risco da Travessia em um trecho } \mathrm{n} \text {; } \\
& R T_{\text {min }}: \text { Valor mínimo de Risco de Travessia identificado na via; } \\
& R T_{\text {max }}: \text { Valor máximo de Risco de Travessia identificado na via. }
\end{aligned}
$$

As equações 1, 2 e 3 foram propostas pelos autores como metodologia para obtenção do Índice de Risco da Travessia (IRT). O resultado final foi categorizado em três níveis de risco para o atravessamento de pedestres, denominados: Baixo, Médio e Alto -obtidos através da classificação dos valores pelo método natural breaks.

Por fim, para avaliar o nível de ajustamento/eficácia do Índice de Risco da Travessia, os resultados foram comparados à ocorrência de atropelamentos registrados no Anel Rodoviário. Esses dados foram extraídos da base de acidentes de trânsito com vítimas de Belo Horizonte disponibilizada pela BHTRANS (2018). A comparação se deu entre o valor obtido para o IRT e a quantidade de atropelamentos (com e sem vítimas fatais) por quilômetro de trecho.

\section{Análise e interpretação dos resultados}

No total, para toda a extensão da rodovia, foram identificadas 14.627 viagens a pé de travessia do Anel Rodoviário, por dia, sendo 7.170 da margem esquerda para a direita e 7.457 no sentido oposto, para o ano de 2012. Os cartogramas, expostos na Figura 3 , permitem observar as áreas de maiores fluxos de pedestres, tanto com origem na margem direita quanto na margem esquerda, distribuídas de forma bem irregular ao longo da rodovia. 

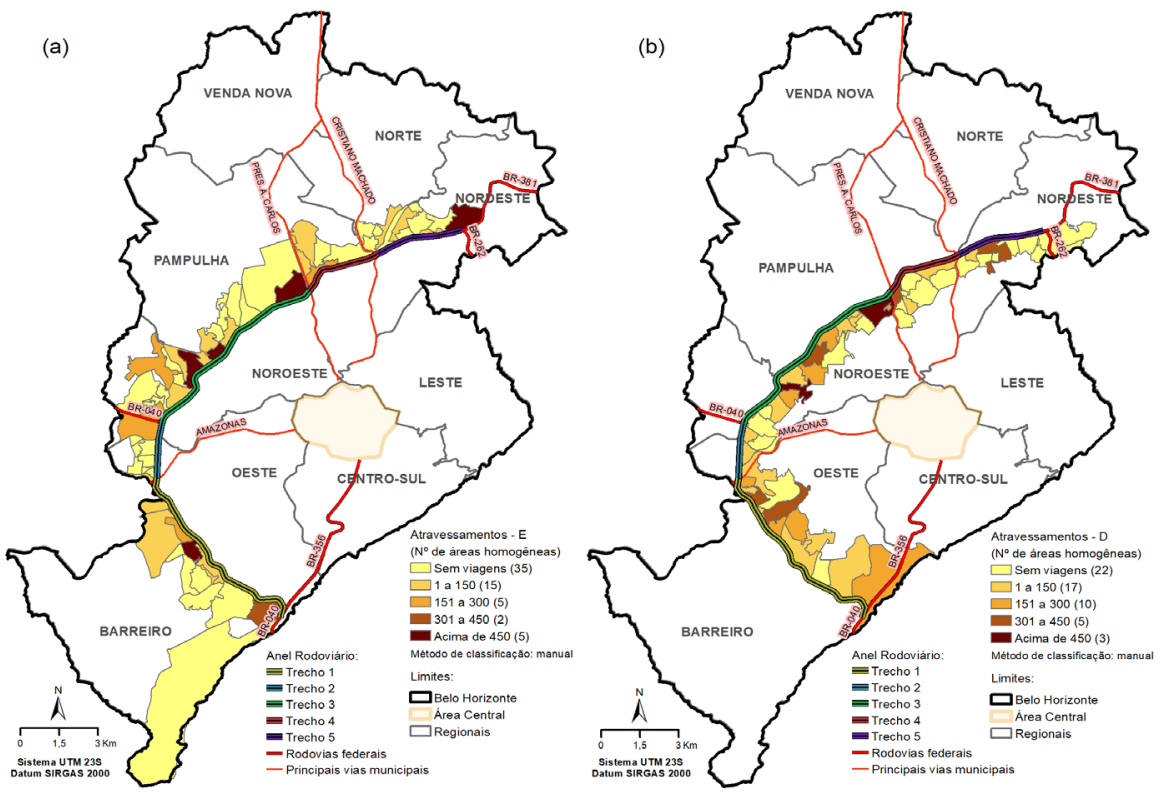

Figura 3. Viagens pelo modo a pé no Anel Rodoviário Celso Mello Azevedo, considerando a origem na margem esquerda (a) e origem na margem direita (b). Fonte: Elaboração própria.

No sentido das viagens com origem na margem esquerda e destino na margem direita (cartograma a), chama atenção sete áreas homogêneas com a quantidade de deslocamentos a pé superior a 300 , localizadas nas proximidades dos bairros: Bairro Novo das Indústrias (711 atravessamentos), Madre Gertrudes (448) e Olhos D’Água (379) (Trecho 1); Jardim Alvorada (1037), Bairro São Francisco (793) e Jardim São José (656) (Trecho 3); Nazaré (563) (Trecho 5). Destacam-se, ainda, 35 AH's sem viagens pelo modo a pé e 15 áreas em que foram computados de 1 a 150 atravessamentos por dia. Cinco áreas homogêneas registraram de 151 a 300 atravessamentos por dia, sendo estas: Bairro das Indústrias I (163 atravessamentos) (Trecho 1); Califórnia (240) (Trecho 2); Conjunto Califórnia I (229) e Novo Glória (295) (Trecho 3); Universitário (291) (Trecho 4). Vale ressaltar que o Trecho 3, onde encontram-se cinco das doze AH's de maior atravessamento de pedestres, está localizado entre a BR-040 e a Av. Presidente Antônio Carlos, importantes corredores de transporte e acesso aos municípios da porção oeste da Região Metropolitana de Belo Horizonte e ao Vetor Norte do município e da RMBH, respectivamente.

No sentido oposto (cartograma b), em oito áreas homogêneas registrou-se mais de 300 viagens, a saber: Vista Alegre (346 atravessamentos) e Betânia (319) (Trecho 1); Padre Eustáquio (993), Nova Cachoeirinha (559) e Caiçara-Adelaide (390) (Trecho 3); Cachoeirinha (304) (Trecho 4); Vila da Luz (593) e Maria Goretti (318) (Trecho 5). Cabe ressaltar que cinco AH's estão localizadas imediatamente na margem oposta das áreas de maior movimentação no sentido esquerda/direita. Em dez AH’s foram identificadas de 151 a 300 viagens, localizadas próximas aos bairros: Belvedere (293 atravessamentos), Betânia (244), Estrela do Oriente (237), Olhos D’Água (208) e Madre Gertrudes (153) (Trecho 1); Vila Nova Cachoeirinha (291), Alto Caiçaras (237), João Pinheiro (225), Minas Brasil (215) e Monsenhor Messias (197) (Trecho 3). O Trecho 1 , por sua vez, está localizado na divisa entre as regionais Oeste e Barreiro e contempla um importante comércio local e ocupação residencial em bairros lindeiros ao Anel Rodoviário, como Belvedere, Betânia, Buritis e Olhos D’água. Este trecho se inicia na intersecção com a rodovia BR-356 e a Avenida Nossa Senhora do Carmo, vias utilizadas 
para acesso à Área Central tanto pela população belo-horizontina quanto por moradores dos municípios do eixo sul da RMBH. Também foram identificadas 22 AH's sem viagens entre as margens direta/esquerda e 17 com registros de 1 a 150 viagens, por dia. O quantitativo total de atravessamento de pedestres por trecho também está presente no Quadro 1.

Quadro 1. Estimativa de atravessamento de pedestres (viagens totais) e passarelas disponíveis para execução do percurso por trecho no Anel Rodoviário Celso Mello Azevedo, 2012. Fonte: Elaboração própria. Base de dados: AGÊNCIA RMBH (2012), DNIT (2018).

\begin{tabular}{lccc}
\hline Trecho & $\begin{array}{c}\text { Viagens totais (pessoas/ } \\
\text { dia) }\end{array}$ & Extensão $(\mathrm{km})$ & $\begin{array}{c}\text { Passarelas que atendem } \\
\text { o trecho }(\mathrm{p})\end{array}$ \\
\hline 1 & 4.467 & 8,2 & 7 \\
\hline 2 & 446 & 2,5 & 4 \\
\hline 3 & 6.812 & 8,3 & 9 \\
\hline 4 & 1.025 & 3,1 & 4 \\
\hline Total & 1.877 & 4,0 & - \\
\hline
\end{tabular}

Para transpor as margens do Anel Rodoviário de Belo Horizonte, os pedestres têm à sua disposição um total de 22 passarelas instaladas ao longo de sua extensão, o que representa, em média, uma passarela a cada $1,2 \mathrm{~km}$. O DNIT (2010) estabelece que projetos de passarelas sejam solicitados, particularmente, nos segmentos de rodovia que atravessam extensões urbanas de elevado volume de tráfego e com ocorrência significativa de acidentes envolvendo pedestres, o que é o caso do Anel Rodoviário. Segundo dados disponibilizados pela BHTRANS, em 2018 foram registrados 769 acidentes na via, sendo 63 atropelamentos - destes, 11 foram com vítimas fatais e 52 com vítimas não fatais (BHTRANS, 2018). Apesar disso, o órgão federal não estabelece distância máxima entre duas passarelas, apenas é adotada uma distância mínima de 200 metros.

O Anel Rodoviário possui segregação física contínua entre as duas pistas de tráfego com defensa de concreto do tipo New Jersey. Apesar de disciplinar o tráfego de veículos e evitar a ocorrência de acidades de maior gravidade, como colisões frontais, as defensas de concreto não impedem o atravessamento de pedestres entre as margens da rodovia. Todavia, nas proximidades das passarelas localizadas nos Trechos $1 \mathrm{e} 2$, apenas, nota-se a instalação de gradis metálicos de forma a canalizar os atravessamentos de pedestres para as passarelas, conforme ilustrado na Figura 4. 


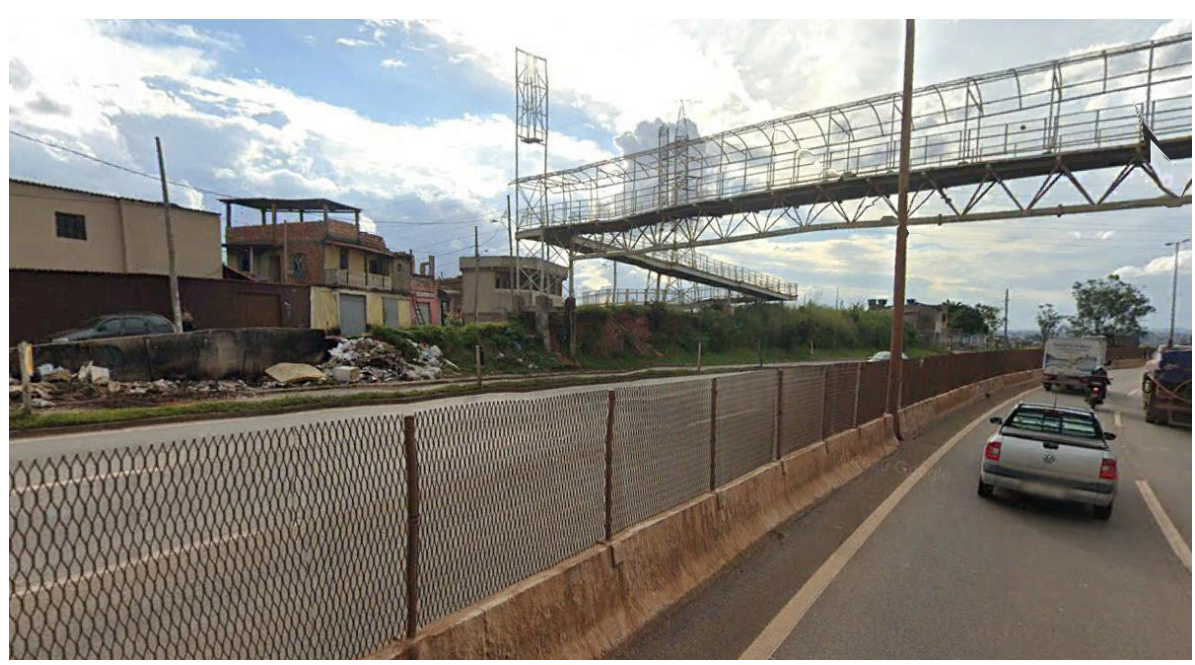

Figura 4. Dispositivos de segregação de pistas utilizados nas proximidades das passarelas instaladas nos Trechos 1 e 2 do Anel Rodoviário Celso Mello Azevedo. Fonte: Google Earth (2020).

Segundo os dados de estimativa de volume médio diário anual do DNIT (2018), apresentados no Quadro 2, o Trecho 2, localizado entre a Av. Amazonas e BR-040, e o Trecho 3, entre BR-040 e Av. Presidente Antônio Carlos, destacam-se por possuírem o tráfego mais elevado, com 105.134 e 54.843 veículos/dia em média, respectivamente, considerando ambos sentidos da via (pista da esquerda -E e pista da direita- $D$, sentido sul-norte). Toda essa demanda reflete diretamente nas condições operacionais da via, principalmente no Trecho 2, classificado com nível de serviço F. De acordo com o Highway Capacity Manual, o nível de serviço F é representado pela presença de fluxo forçado ou em colapso, que ocorre quando a demanda excede a capacidade da via, e consequentemente há ocorrência de operação dentro das filas (congestionamentos) (TRB, 2000).

Quadro 2. Estimativa de volume médio diário anual (VMDa) de veículos por trecho no Anel Rodoviário Celso Mello Azevedo, 2018. Fonte: Elaboração própria. Base de dados: DNIT (2018).

\begin{tabular}{lcccccc}
\hline Trecho & $\begin{array}{c}\text { ID__ } \\
\text { TRECHO } \\
\text { DNIT }\end{array}$ & $\begin{array}{c}\text { Extensão } \\
(\mathrm{km})\end{array}$ & $\begin{array}{c}\text { VMDa_E } \\
(\text { veíc/dia) }\end{array}$ & $\begin{array}{c}\text { VMDa_D } \\
\text { (veíc/dia) }\end{array}$ & $\begin{array}{c}\text { Nível de } \\
\text { serviço - E }\end{array}$ & $\begin{array}{c}\text { Nível de } \\
\text { serviço - D }\end{array}$ \\
\hline 1 & 151384 & 8,2 & 10.306 & 13.675 & $\mathrm{~A}$ & $\mathrm{~B}$ \\
\hline 2 & 151383 & 2,5 & 52.134 & 53.000 & $\mathrm{~F}$ & $\mathrm{~F}$ \\
\hline 3 & 154416 & 8,3 & 28.132 & 26.712 & $\mathrm{C}$ & $\mathrm{C}$ \\
\hline 5 & 154415 & 3,1 & 7.064 & 2.022 & $\mathrm{~A}$ & $\mathrm{~A}$ \\
\hline & 154414 & 4,0 & 9.422 & 9.929 & $\mathrm{~A}$ & $\mathrm{~A}$ \\
\hline
\end{tabular}

Ao relacionar o fluxo de veículos e a possibilidade de transposição de maneira segura, pela presença de passarelas, com a quantidade de viagens potências na barreira, foi possível auferir o Risco da Via (RV) e o Risco da Travessia (RT), calculados pelas Equações 1 e 2, conforme apontado no Quadro 3. A partir dessas informações e com a aplicação da Equação 3, obtém-se o Índice de Risco da Travessia (IRT) que demonstra os níveis de risco ao transpor a rodovia em cada trecho (Figura 5). 
Quadro 3. Estimativas de volume de veículos, atravessamentos e dos riscos da Via (RV) e da Travessia (RT), por trecho, no Anel Rodoviário Celso Mello Azevedo. Fonte: Elaboração própria.

\begin{tabular}{lcccccc}
\hline Trecho & $\begin{array}{c}\text { Extensão } \\
(\mathrm{km})\end{array}$ & $\begin{array}{c}\text { VMDa total } \\
(\text { veíc/dia })\end{array}$ & $\begin{array}{c}\text { Passarelas } \\
\text { que atendem } \\
\text { o trecho }(\mathrm{p})\end{array}$ & $\begin{array}{c}\text { Viagens total } \\
\text { (pessoas/ } \\
\text { dia) }\end{array}$ & $\begin{array}{c}\text { Risco da } \\
\text { Via (RV) }\end{array}$ & $\begin{array}{c}\text { Risco da } \\
\text { Travessia (RT) }\end{array}$ \\
\hline 1 & 8,2 & 23.981 & 7 & 4.467 & 60 & 32.513 \\
\hline 2 & 2,5 & 105.134 & 4 & 446 & 2.628 & 468.898 \\
\hline 4 & 8,3 & 54.843 & 9 & 6.812 & 82 & 66.951 \\
\hline 5 & 3,1 & 9.086 & 4 & 1.025 & 183 & 60.569 \\
\hline & 4,0 & 19.351 & 3 & 1.877 & 538 & 252.235 \\
\hline
\end{tabular}

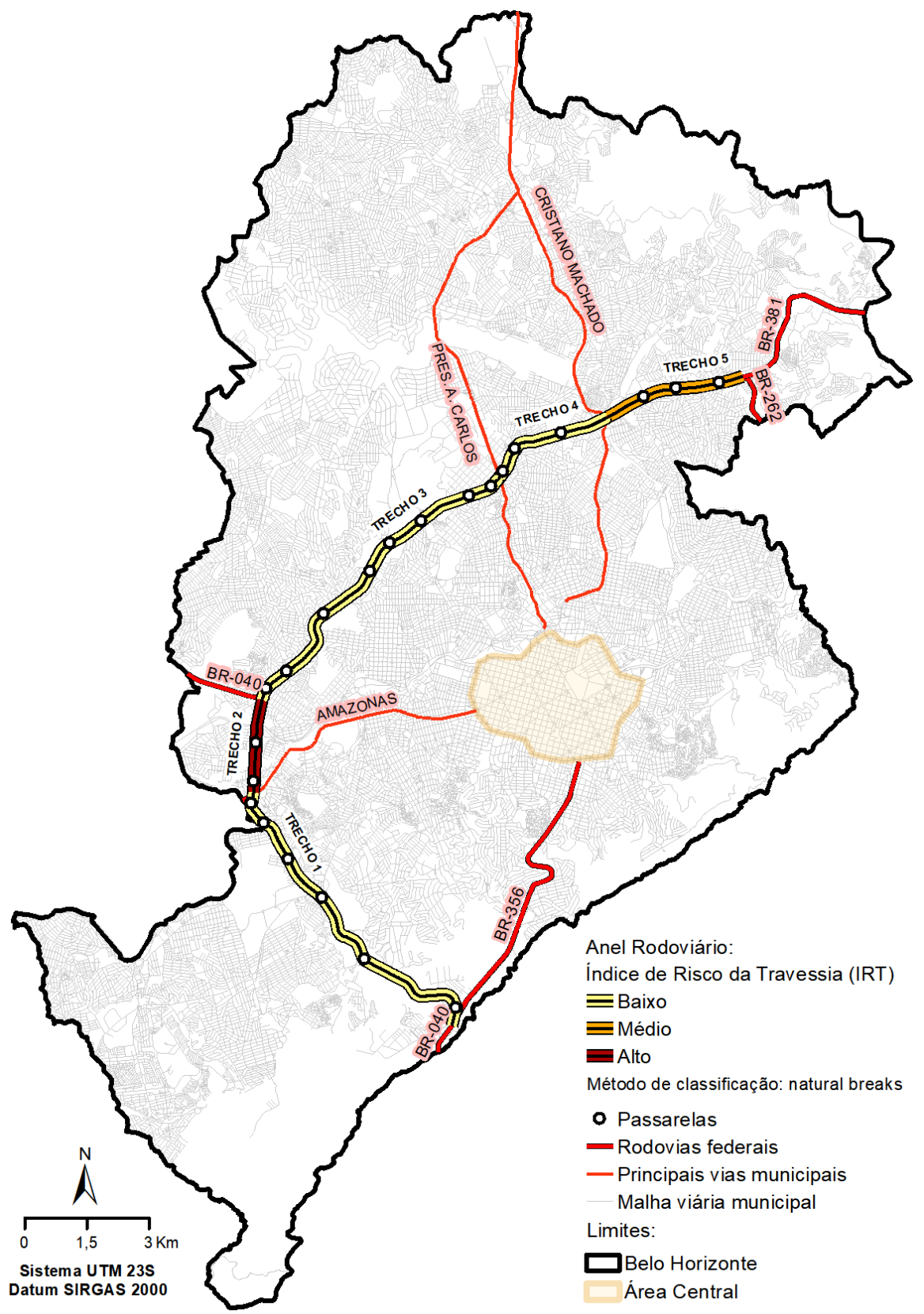

Figura 5. Índice de Risco da Travessia (IRT). Fonte: Elaboração própria. 
Destaca-se que o Trecho 2 foi classificado como o de maior risco aos pedestres, ainda que tenha menor extensão e menor quantidade de atravessamentos, dada a menor densidade populacional do entorno. Localizado entre o acesso à BR-040 e a Av. Amazonas, vias de ligação à Área Central e a importantes municípios da região metropolitana, como Contagem e Betim, constata-se que o fator primordial para esse resultado se deve ao elevado fluxo de veículos, superior a 105 mil veículos/dia em média (DNIT, 2018). No entanto, nota-se um contraponto entre o IRT e as ocorrências de atropelamentos no trecho. Em 2018 foram registrados nesse segmento da rodovia 2 atropelamentos, sendo uma vítima fatal, o que representa 0,8 atropelamento por quilômetro. Esse cenário pode ser justificado pela presença de gradis metálicos instalados junto às defensas de concreto, tornando-se obstáculos à travessia em nível e, dessa forma, inibindo os atravessamentos fora das passarelas. A baixa ocorrência de atropelamentos também é observada no Trecho 1, segmento da rodovia que apresenta a mesma estrutura de segregação entre as pistas.

Por sua vez, o Trecho 5 foi classificado com risco médio. Mesmo não apresentando a maior quantidade de tráfego diário entre os trechos, com cerca de 19 mil veículos/dia, nem a maior quantidade de atravessamentos, aproximadamente 1,8 mil por dia, este trecho teve a maior ocorrência de atropelamentos, totalizando 24 - o que corresponde a uma média de 6 atropelamentos por quilômetro. Diferentemente do Trecho 2, o Trecho 5 não dispõe das telas metálicas que impedem os atravessamentos dos pedestres. Soma-se a isso a baixa oferta de passarelas ao longo de sua extensão, resultando em um cenário trágico com o registro de quatro atropelamentos com vítimas fatais no ano de 2018, o que corresponde a 38\% dos atropelamentos com vítimas fatais no Anel Rodoviário e 9\% das ocorrências no município de Belo Horizonte (BHTRANS, 2018).

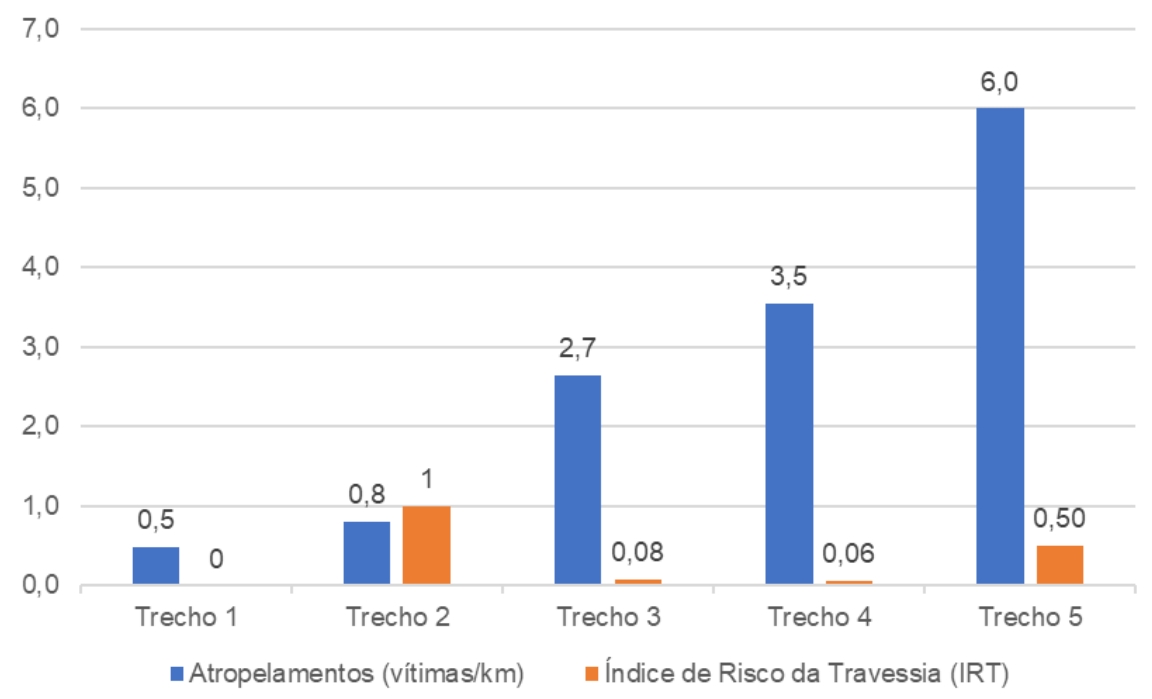

Figura 6. Índice de Risco da Travessia (IRT) e os atropelamentos por quilômetro, por trecho, no Anel Rodoviário Celso Mello Azevedo, 2018. Fonte: Elaboração própria. Base de dados: BHTRANS (2018).

Em contrapartida, os Trechos 1, 3 e 4 foram classificados com baixo risco aos pedestres. Ao analisar as ocorrências de atropelamentos, nota-se que o Trecho 1 possui a menor incidência por quilômetro da via, 0,5 por quilômetro. Os Trechos 3 e 4 registraram, respectivamente, 2,7 e 3,5 atropelamentos por quilômetro. O Trecho 3 possui ainda a maior quantidade de viagens pelo modo a pé (6.812), porém, também é o trecho com maior disponibilidade de passarelas, o que interfere diretamente na classificação do risco no local. Mesmo assim, expressivos registros de atropelamentos são observados ao longo dos Trechos 3 e 4, podendo ser relacionados, assim como no Trecho 5, com a 
inexistência de uma estrutura de canalização do fluxo de pedestres para as passarelas. Cabe ressaltar que nesses trechos estão localizadas as principais avenidas destacadas no presente estudo (Av. Amazonas, Av. Presidente Antônio Carlos e Av. Cristiano Machado), dentre outras vias arteriais de extrema importância para cidade. Além disso, a barreira socioespacial gerada pelo Anel Rodoviário, mesmo que se reflita em um risco relativamente moderado para o atravessamento de pedestres nestes locais, seguindo o método de avaliação proposto, ainda é muito impactante e se reflete na constante ocorrência de atropelamentos.

\section{Considerações finais}

A presença de uma infraestrutura rodoviária dentro do espaço urbano gera diversos transtornos, não raro evidencia ou reforça os conflitos inerentes entre pessoas e veículos, de modo que o tráfego de veículos e a própria via se tornem obstáculos à mobilidade e acessibilidade. Nesse sentido, o presente estudo, ao analisar o caso do Anel Rodoviário Celso Mello Azevedo, com base no conceito de efeito barreira, oferece informações ao debate necessário sobre as relações sociais mais amplas no território das grandes cidades, que envolve contradições entre o espaço dos veículos e das pessoas.

Mouette e Waisman (2004), explicitam que o efeito barreira ocorre devido a presença de elementos causadores, elementos de influência e dos impactos decorrentes. Analogamente, o Anel Rodoviário pode ser considerado tanto um elemento causador como de influência, pela própria infraestrutura e condições/necessidade de circulação da população. Também envolve os impactos, uma vez que estes podem ser relacionados à restrição e falta de acessibilidade entre as margens da via causadas pela presença da mesma. Trata-se de um exemplo de uma manifestação de conflito no processo de produção do espaço, dado que suas características de rodovia foram claramente substituídas por de uma via urbana, tanto pela quantidade expressiva de atravessamentos quanto pelas consequências que a falta de um ambiente propício para tal causa aos pedestres, traduzidos no cenário alarmante de atropelamentos registrados no local.

Nesse sentido, os objetivos propostos para análise do Anel Rodoviário, com a estimativa do volume dos atravessamentos e avaliação do risco potencial de travessia de pedestres, foram cumpridos, evidenciando os trechos de maior atenção para o deslocamento a pé ao considerar os fluxos de atravessamentos, o volume médio diário de veículos e a presença de dispositivos para uma travessia segura - no caso, as passarelas. Ressalta-se que a pesquisa apresenta limitações devido a indisponibilidade de um banco de dados que contemple informações relacionadas ao mesmo ano para estas três dimensões de análise. No entanto, mesmo diante deste cenário, conclui-se que a proposta de análise aqui apresentada trás avanços para área e permite que, posteriormente, a avaliação de risco potencial de travessia seja atualizada à medida que a pesquisa OD, que ocorre decenalmente, também seja atualizada.

Ressalta-se, ainda, que velocidades operacionais entre 60 e $80 \mathrm{~km} / \mathrm{h}$, como as regulamentadas no Anel Rodoviário, são consideradas baixas e pouco perigosas em rodovias que operam com essa função, porém, esses valores mostram-se totalmente incompatíveis em áreas urbanas, especialmente no compartilhamento espacial com os fluxos a pé. As áreas de maior movimentação de pessoas, normalmente associadas com a estrutura urbana local utilizada para a transposição dessa barreira e a diversidade e irregularidade de trajeto que os pedestres se inserem, os expõem a riscos elevados. O Índice de Risco da Travessia, bem como as análises dos atravessamentos no Anel Rodoviário de Belo Horizonte, permitiu colocar em pauta a discussão sobre as condições de movimentação dos pedestres entre as margens da via, que acaba se tornando uma barreira 
socioespacial entre as comunidades do entorno e um obstáculo aos deslocamentos das pessoas. A partir do passo inicial dado pelo presente estudo, faz-se necessário destacar a importância de não se esgotar o debate sobre o assunto. Fatores como as condições socioeconômicas dos moradores do entorno, as características do uso e ocupação do solo, o comportamento dos pedestres, os desejos de acesso, a densidade de ocupações irregulares, entre outros, podem agregar elementos importantes para a discussão sobre os obstáculos (e riscos) impostos por rodovias inseridas no espaço urbano. 


\section{Q Bibliografia}

》 Agência RMBH (2012). Relatório Completo Pesquisa OD 2012 e base de dados. Agência de Desenvolvimento da Região Metropolitana de Belo Horizonte, Governo do Estado de Minas Gerais. Disponível em: http://www.agenciarmbh. mg.gov.br/wp-content/uploads/2016/o6/Relatorio-Completo-PesquisaOD-2012-1.pdf (20/11/2019).

»Anciaes, P. R.; Boniface, S.; Dhanani, A.; Mindell, J. S. e Groce, N. (2016). Urban transport and community severance: Linking research and policy to link people and places. Journal of Transport \& Health, vol. 3, ed. 3, p. 268-277.

»Anciaes, P. R.; Jones, P. e Metcalfe, P. J. (2018). A stated preference model to value reductions in community severance caused by roads. Transport Policy, vol. 64, p. 10-19.

» Andrade, R. Q.; Libânio, A. A. C.; Bessa Júnior, J. E. e Coelho, R. S. (2019). Avaliação do impacto da velocidade regulamentar no desempenho operacional do Anel Rodoviário de Belo Horizonte. In: Anais $33^{\circ}$ Congresso de Pesquisa e Ensino em Transportes da ANPET, Balneário Camburiú, p. 3434-3441.

» Belo Horizonte (2011). Lei № 10.134, de 18 de março de 2011. Institui a Política Municipal de Mobilidade Urbana. Prefeitura Municipal de Belo Horizonte. Disponível em: http://portal6.pbh.gov.br/dom/iniciaEdicao.do?method=Deta IheArtigo\&pk=1054553 (17/11/2019).

"Belo Horizonte (2020). BH MAP: Base de dados georreferenciados da Prefeitura de Belo Horizonte. 2020. Disponível em: http://bhmap.pbh.gov.br/(30/12/2020).

»BHTRANS (2008). Edital de Concorrência № 131/2008: Anexo III-Requisitos Mínimos para Prestação dos Serviços. Empresa de Transportes e Trânsito de Belo Horizonte S. A., Prefeitura de Belo Horizonte. Disponível em: https://prefeitura. pbh.gov.br/sites/default/files/imagens/authenticated\%2C\%2oeditor_a_ bhtrans/080318_Requisitos_mC3ADnimos_anexo_III.pdf(19/11/2019).

"BHTRANS (2018). Dados aberto: dados de acidentes de trânsito com vítima ocorridos nas vias municipais ou nas vias de Belo Horizonte. Empresa de Transportes e Trânsito de Belo Horizonte S. A., Prefeitura Municipal de Belo Horizonte. Disponível em: https://prefeitura.pbh.gov.br/bhtrans/informacoes/ dados/dados-abertos (19/01/2021).

"Cardoso, L. (2007). Transporte público, acessibilidade urbana e desigualdades socioespaciais na Região Metropolitana de Belo Horizonte. Tese (Doutorado, Programa de Pós-graduação em Geografia), Departamento de Geografia, Universidade Federal de Minas Gerais, Belo Horizonte.

»Carlos, A. F. A. (2015). A reprodução do espaço urbano como momento da acumulação capitalista. Crise urbana, p. 25-36.

»CNT. (2018). Anuário CNT do Transporte 2018: estatísticas consolidadas. Confederação Nacional do Transporte. Disponível em: http:// anuariodotransporte.cnt.org.br/2018/Inicial (26/11/2019).

»Costa, P. B.; Neto, G. C M. e Bertolde, A. I. (2017). Urban mobility indexes: a brief review of the literature. Transportation Research Procedia, v. 25 C, p. 36493659.

»DNIT (2010). Publicação IPR - 740: Manual de Projeto Geométrico em Travessias 
Urbanas. Departamento Nacional de Infraestrutura de Transportes, Ministério dos Transportes. Rio de Janeiro: IPR, 2010. p. 392.

" DNIT (2018). Plano Nacional de Contagem de Tráfego: Estimativa do Volume Médio Diário Anual - VMDa 2018. Departamento Nacional de Infraestrutura de Transportes, Ministério dos Transportes. Disponível em: http://servicos.dnit. gov.br/dadospnct/Modelagem (30/03/2020).

"Grisolía, J. M.; López, F. e Ortúzar, J. D. (2014). Burying the Highway: The Social Valuation of Community Severance and Amenity. International Journal of Sustainable Transportation, v. 9, n.4, p. 298-309.

» Maciorowski, M. M. (2018). Vias urbanas e transportes não motorizados: o efeito barreira e os desafios na busca da mobilidade urbana sustentável. Dissertação (Mestrado em Engenharia de Transportes e Gestão Territorial), Universidade Federal de Santa Catarina, Florianópolis.

"Malatesta, M. (2017). Caminhabilidade e segurança: O desafio do desenho urbano nas cidades brasileiras. In: Andrade, V. e Linke, C. C (Orgs). Cidade de Pedestres: a caminhabilidade no Brasil e no mundo. Rio de Janeiro: Babilonia Cultura Editorial, 2017. cap. 6, p. 69-82.

"Martine, G. e McGranahan, G. (2010). A transição urbana brasileira: trajetória, dificuldades e lições aprendidas. In: BENINGER, R. (Org.). População e Cidades: subsídios para o planejamento e para as políticas sociais. Campinas: Núcleo de Estudos de População-Nepo/Unicamp; Brasília: UNFPA.

" Mindell, J. S. e Anciaes, P. R. (2020). Transport and community severance. In: Advances in Transportation and Health, cap. 7, p. 175-196.

» Mindell, J. S. e Karlsen, S. (2012). Community Severance and Health: What Do We Actually Know? Journal of Urban Health, vol. 89, p. 232-246.

" Miranda, G. C.; Pena, M. S.; Ramos, J. R. L. e Elmiro, M. A. T. (2017). Uso de imagens Rapideye e análise multicritério na construção de traçados para o contorno sul do rodoanel de Belo Horizonte. Geografias, Edição Especial: II Simpósio Modelagem de Sistemas Ambientais e Gestão da Paisagem: Desafios e aplicações, Belo Horizonte, p. 119-130.

» Moreira, C. M. e Brasil, J. C. (2019). Plano de logística metropolitano: principais resultados do diagnóstico do deslocamento de cargas na Região Metropolitana de Belo Horizonte. In: Anais $33^{\circ}$ Congresso de Pesquisa e Ensino em Transportes da ANPET, Balneário Camburiú, p. 2318-2329.

» Mouette, D., Waisman, J. (2004). Proposta de uma metodologia de avaliação do efeito barreira. Revista dos Transportes Públicos - ANTP, São Paulo, v. 26, p. 33-54.

»Pooler, J. A. (1995). The use of spatial separation in the measurement of transportation accessibility. Transportation Research A, v. 29A, n. 6, p. 421-427.

» Silva Júnior, S. B. e Ferreira, M. A. G. (2008). Rodovias em áreas urbanizadas e seus impactos na percepção dos pedestres. Sociedade $\&$ Natureza, Uberlândia, v. 1, n. 20, p. 221-237.

"Sousa, M. T. R. e Braga, R. (2011). As influências do efeito de barreira na dinâmica das cidades: o caso da cidade de Rio Claro-SP. Geografia Ensino \& Pesquisa, Santa Maria, v. 15, n. 1, p. 53-70.

» TRB (2010). Highway Capacity Manual. 5 ed. Transportation Research Board, TRB Publications. 2010. p. 311.

»Vasconcellos, E. A. (2006). Transporte e meio ambiente: conceitos e informações 
para análise de impactos. São Paulo: Ed. do Autor, 2006. p. 200.

"Vaughan, L.; Anciaes, P. e Mindell, J. (2020). Cars, conflict and community severance. In: Appleyard, B. (Ed.) Livable Streets 2.o, Elsevier, cap. 9.

»Villaça, F. (1998). Espaço intra-urbano no Brasil. São Paulo: Studio Nobel, 1998, cap.5, p. 113-134.

\section{Bárbara Abreu Matos / b.abreumatos@gmail.com}

Engenheira Civil, Mestre em Transportes e Doutoranda em Geografia (Universidade Federal de Minas Gerais). Professora do Departamento de Engenharia Urbana da Universidade Federal de Ouro Preto (DEURB/UFOP), atuando na área de Planejamento e Organização do Sistema de Transporte.

\section{Carlos Lobo / carlosfflobo@gmail.com}

Doutor em Geografia pela Universidade Federal de Minas Gerais e Pós-Doutor em Demografia pelo NEPO/UNICAMP. Professor Associado do Departamento de Geografia do IGC/UFMG e coordenador do Programa de Pós-graduação em Geografia do Instituto de Geociências da UFMG. Atua preferencialmente na subárea de Geografia da População e Geografia dos Transportes, especialmente nas linhas de pesquisa migrações e mobilidade espacial da população. 